\title{
Drug utilisation pattern of antihistamines in upper respiratory tract infections in paediatric patients \\ Bharati JP, ${ }^{1}$ iD $\triangle$ Ulak S, ${ }^{2}$ iD Keshari A, ${ }^{3}$ iD Acharya A, ${ }^{4}$ iD
}

${ }^{1}$ Jyoti Prabha Bharati; ${ }^{4}$ Anna Acharya, Lecturer, Department of Pharmacology, Kathmandu Medical College and Teaching Hospital, Duwakot, Bhaktapur, Nepal; ${ }^{2}$ Sanjay Ulak, Consultant, Department of Paediatrics, Bhaktapur Hospital, Dudhpati, Bhaktapur, Nepal; ${ }^{3}$ Aniket Keshari, Undergraduate Medical Student, Kathmandu Medical College and Teaching Hospital, Sinamangal, Kathmandu, Nepal.

\begin{abstract}
Background: Upper respiratory tract infections (URTIs) are the most common infections in the paediatric population leading to health care consultations. Antihistamines are commonly prescribed medicines in children.

Objectives: This study attempted to assess the current prescription patterns of antihistamines used in the treatment of URTIs.

Methods: A descriptive cross-sectional study was conducted in the outpatient paediatric department of Kathmandu Medical College from January 2020 to January 2021. Ethical approval was taken from Institutional Review Committee of Kathmandu Medical College. A convenient sampling technique was used. The data were collected from the outpatient department prescription card into a suitably designed proforma. Drug use indicator developed by the World Health Organisation for Rational Use of Drugs was utilised. Data were analysed using SPSS v.20.

Results: Data from prescriptions of 345 patients aged less than 14 years were collected from the paediatric outpatient department of KMCTH. The most common condition was common cold (132, 38.26\%). Most commonly prescribed antihistamines were Fexofenadine (156, 45.21\%). Average number of drugs per prescription was 2.31. The total number of drugs prescribed by generic name was 128 (16\%). Antibiotics made its place in prescriptions 279 (34.96\%) times. No parenteral medication was used and 140 (17.5\%) of all drugs prescribed were from the National List of Essential Medicines. Conclusion: Antihistamines, mostly second generation, were commonly prescribed in URTIs in paediatric patients. Majority of WHO indicators were within normal limits while some needed marked improvement. Different programmes can be implemented for improvement in prescribing patterns and promotion of rational drug use.
\end{abstract}

Key words: Antihistamines; Drug utilisation; Paediatric patients; Upper respiratory tract infections.

Access this article online

Website: www.jkmc.com.np

DOI: https://doi.org/10.3126/jkmc.v10i1.38968

\section{HOW TO CITE}

Bharati J, Ulak S, Keshari A, Acharya A. Drug utilisation pattern of antihistamines in upper respiratory tract infections in paediatric patients. J Kathmandu Med Coll. 2021;10(1):28-32.

Address for correspondence

Dr. Jyoti Prabha Bharati

Lecturer, Department of Pharmacology,

Kathmandu Medical College and Teaching Hospital,

Duwakot, Bhaktapur, Nepal.

E-mail:jtbharati@gmail.com

Copyright ๔ 2021 Journal of Kathmandu Medical College (JKMC)

ISSN: 2019-1785 (Print), 2091-1793 (Online)

(i) (S) This work is licensed under a Creative Commons Attribution-Non Commercial 4.0 International License.

\section{INTRODUCTION}

rug utilisation research is defined by World Health Organisation (WHO) as "the marketing, distribution, prescription, and use of drugs in a society, with special emphasis on the resulting medical, social, and economic consequences."1 Rational prescribing implies, using right drug for right patient at right time in right dose, and manner of administration at affordable cost with right information. ${ }^{2}$

Drug utilisation study is important for clinical, educational, and economical purposes as well as for proper distribution and effective regulation. Irrational drug prescribing is still in practice all over world, more so in developing countries. ${ }^{3}$ Prescribing patterns should be evaluated periodically to increase therapeutic efficacy, decrease effects and provide feedback to prescribers. ${ }^{4}$ 
Upper respiratory tract infections (URTIs) are the most frequently occurring infections in paediatric population leading to health care consultations. ${ }^{5}$ Though URTIs are mild and self-limiting, antihistamines are prescribed in most cases. ${ }^{6}$ The older first generation $\mathrm{H}_{1}$ antihistamines penetrate brain to cause sedation, drowsiness, fatigue and impaired concentration, so their use should be discouraged. ${ }^{7}$ The second-generation $\mathrm{H}_{1}$-antihistamines are safer, cause less sedation, and are more efficacious. ${ }^{8}$

This study attempted to assess the current prescription pattern of Antihistamines used in URTI treatment to provide relevant and useful feedback to paediatricians and general practitioners.

\section{METHODOLOGY}

A descriptive cross-sectional study was conducted in paediatric outpatient department (OPD) of Kathmandu Medical College Teaching Hospital (KMCTH) from January 2020 to January 2021. Ethical clearance (Ref. 200120203) was obtained from the Institutional Review Committee of Kathmandu Medical College prior to the start of the study. Paediatric patients diagnosed with upper respiratory tract infections visiting paediatric department of KMCTH were asked to participate in the study. Informed consent was taken from parents/ guardians of the participants. The data were collected conveniently from the outpatient OPD prescription card into a suitably designed individual proforma.

The WHO prescribing indicators were used in this study. Prescribing indicators include the total number of drugs prescribed, average number of drugs per prescription, percentage of drugs prescribed by generic name, percentage of antibiotics prescribed, percentage of injections prescribed and the percentage of drugs prescribed from essential drug list of Nepal., ${ }^{910}$ The sample size was calculated using the formula:

$\mathrm{n}=\mathrm{Z}^{2} \mathrm{pq} / \mathrm{e}^{2}=1.96^{2 *}(0.246)^{*}(0.754) /(0.05)^{2}$

Where, $Z=1.96$ (at $95 \%$ confidence limit); $p=0.246$ $(24.6 \%)$; assuming $\mathrm{p}$ of antihistamine prescription $24.6 \% ;^{2} \mathrm{q}=1-\mathrm{p}=1-0.24 .6=0.754$; allowable error $(\mathrm{e})=$ $0.05(5 \%)$. The sample size was calculated to be $285.02 \approx$ 286 . Adding $20 \%$ of non-response rate, the total sample size estimated was $342.02 \approx 345$.

The data included demographic information of the patient along with total number, dose, dosage form, frequency, route, and duration of prescribed antihistamine. All the data were then imported into Microsoft Excel Sheet and analysed in IBM Statistical
Package for Social Sciences (SPSS) Statistics for Windows, version 20 (IBM Corp., Armonk, N.Y., USA). Descriptive analysis was done. Frequency and percentage were calculated and expressed in tables and figures.

\section{RESULTS}

A total of 345 patients of upper respiratory tract infections were enrolled among which 182 (52.8\%) were male (Table 1). Majority of the children diagnosed with URTIs were preschoolers 137 (39.5\%) and school-aged 96 (28\%) (Figure 1).

Most common conditions were common cold (132, $38.26 \%)$ followed by viral URTIs, pharyngitis, tonsillitis, allergic rhinitis, laryngitis, sinusitis, and otitis media (Table 2).

Most commonly prescribed antihistamines were fexofenadine $(156,45.21 \%)$ followed by cetirizine, chlorpheniramine, levocetirizine, and pheniramine. Chlorpheniramine and pheniramine were given only in combination formulations as Chlorpheniram ine+dextromethorphan+phenylephrine (26, 7.53\%), Chlorpheniramine +pseudoephedrine+paracetamol $(22,6.37 \%)$ and pheniramine+dextromethorphan (19, $5.50 \%)$.

A total of 798 drugs were prescribed for 345 patients, the average number of drugs per prescription was 2.31 with a range between 1 and 4 . The total number of drugs prescribed by generic name was $128(16 \%)$. An antibiotic was given 279 (34.96\%) times in various prescriptions. None of the patients received a drug by parenteral route and only few drugs prescribed from essential drug list of Nepal (Table 4). It was found that 448 (56\%) were prescribed in syrups, $223(28 \%)$ in tablets, and $127(16 \%)$ in oral drops. The average cost of antihistamine was found to be Rs. 53.14.

\section{Table 1: Demographic profile of antihistamine} prescribed patients $(n=345)$

\begin{tabular}{|cc|}
\hline Sex & Frequency (\%) \\
\hline Male & $182(52.8)$ \\
\hline Female & $163(47.2)$ \\
\hline
\end{tabular}

Table 2: Commonly seen conditions in upper respiratory tract infections

\begin{tabular}{|cc|}
\hline Conditions & Frequency (\%) \\
\hline Common cold & $132(38.26)$ \\
\hline Viral URTIs & $74(21.44)$ \\
\hline Pharyngitis & $47(13.62)$ \\
\hline
\end{tabular}




\begin{tabular}{|cc|}
\hline Tonsillitis & $27(7.82)$ \\
\hline Allergic rhinitis & $25(7.24)$ \\
\hline Laryngitis & $18(5.21)$ \\
\hline Sinusitis & $13(3.76)$ \\
\hline Otitis media & $9(2.60)$ \\
\hline
\end{tabular}

Table 3: Commonly prescribed antihistamines

\begin{tabular}{|cc|}
\hline Antihistamines & Frequency (\%) \\
\hline fexofenadine & $156(45.21)$ \\
\hline cetirizine & $92(26.66)$ \\
\hline chlorpheniramine & $48(14)$ \\
\hline levocetirizine & $30(8.6)$ \\
\hline pheniramine & $19(5.50)$ \\
\hline
\end{tabular}

Table 4: Prescribing indicators among outpatients

\begin{tabular}{lcc}
\hline $\begin{array}{l}\text { Indicators } \\
\text { Total number of } \\
\text { prescriptions analysed }\end{array}$ & 345 & $\begin{array}{c}\text { WHO optimal } \\
\text { limit }\end{array}$ \\
\hline $\begin{array}{l}\text { Total number of drugs } \\
\text { prescribed }\end{array}$ & 798 & \\
$\begin{array}{l}\text { Average number of drugs } \\
\text { per prescription }\end{array}$ & 2.31 & $1.6-1.8$ \\
$\begin{array}{l}\text { Drugs prescribed by } \\
\text { generic name }\end{array}$ & $128(16 \%)$ & $100 \%$ \\
$\begin{array}{l}\text { Percentage of an } \\
\text { antibiotic prescribed }\end{array}$ & $279(34.96 \%)$ & $20.0-26.8 \%$ \\
$\begin{array}{l}\text { Percentage of an } \\
\text { injection prescribed }\end{array}$ & - & $13.4-24.1 \%$ \\
\hline $\begin{array}{l}\text { Percentage of drugs from } \\
\text { essential drug list of Nepal }\end{array}$ & $140(17.54 \%)$ & $100 \%$ \\
\hline
\end{tabular}

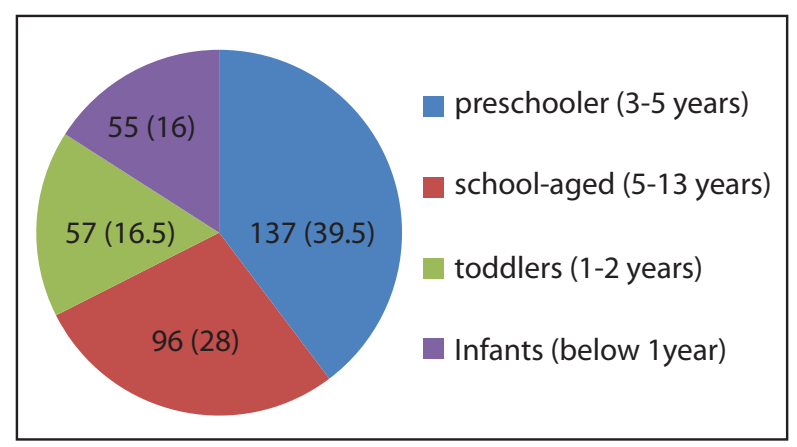

Figure 1: Age distribution among patients who were prescribed antihistamines

\section{DISCUSSION}

In the present study most of the patients with the diagnosis of upper respiratory tract infections were under six years of age $(249,72.17 \%)$ which was similar to the study done by Tiwari et al. at Punjab where $80 \%{ }^{11}$ commonly in children who attend preschool and school. Children's immune systems are not fully developed, so the incidence of respiratory infections is high in children under age of six years who are more susceptible to URTIs in comparison to other age groups. Our study showed the most commonly seen URTIs condition in children was common cold 132 (38.26\%) which was similar to the study done by Zeru et al. ${ }^{12}$ with 83 (39.0\%). Antihistamines are the most commonly prescribed medicine in paediatric patients. ${ }^{13}$ In the present study commonly prescribed antihistamines were fexofenadine, cetirizine, chlorpheniramine, levocetirizine, and pheniramine. This shows that second generation antihistamines were prescribed more frequently compared to first generation drugs which is similar to the study done by Kolasani et al. ${ }^{14}$ where cetirizine (59.2\%) was the most commonly prescribed $\mathrm{H} 1$ antihistamine drug.

Second generation drugs are safer, does not show central nervous system and anticholinergic side effects such as sedation and dry mouth, which are commonly seen in the first-generation antihistamines. ${ }^{15}$ Their longer duration of action also makes more patientfriendly and increases patient compliance. ${ }^{16}$ In present study 67 (19.42\%) of the antihistamines were prescribed as fixed dose combinations; Chlorpheniramine+ dextromethorphan+phenylephrine $(26,7.53 \%)$, Chlorp heniramine+pseudoephedrine+paracetamol $(22,6.37 \%)$ and pheniramine+dextromethorphan (19, 5.50\%) similar to study of Tiwari et al. ${ }^{11}$ Cetrizine+ambroxol combination was found to be the most commonly prescribed combination (28\%) followed by combination of Chlorpheniramine+phenylephrine (18\%).

The rational use of drugs demands to keep the number of drugs prescribed as low as possible to reduce the cost of treatment, drug interaction, and adverse effects. In this study, the average number of drugs prescribed was 2.31 similar to results of Das et al. in paediatric outpatient settings which reported the average number of drugs prescribed as $2.37^{17}$ whereas WHO recommends optimal level to be1.6-1.8.

Present study showed 128 (16\%) drugs were prescribed by generic name which is less than the study of Mirza et al. ${ }^{18}$ in southern India where it was 30\% (optimal value being $100 \%$ ). Lesser number of prescriptions by generic name could be due to branded drugs being easily available and names are easy to recall for the prescriber and dispenser. ${ }^{19}$ The antibiotics also had fair share (279, $34.96 \%$ ) in prescriptions, lesser then $52 \%$ reported by 
Senok et al. ${ }^{20}$ just a little higher than WHO optimal level of $20-26.8 \%$. Oral route is the most convenient and safest route of drug administration among children. The most commonly used dosage form was syrup in 448 (56.23\%) followed by tablets in $223(28 \%)$, and oral drops in $127(16 \%)$. The result was found comparable to the study carried out by Karande et al. in which $61 \%$ of the drugs were prescribed in the form of syrup. ${ }^{21}$ The cost of prescription increases as the number of injection and antimicrobial drugs in the prescription increase. In this study, no parenteral medication was used which may be due to OPD patients study. The National List of Essential Medicines (NLEM) is prepared by the country which includes effective and safe medicines in order to meet patients need. ${ }^{22}$ The NLEM drugs are dispensed free of cost from government health facilities. Present study findings showed that only $140(17.5 \%)$ of prescribed drugs were from essential drugs which is much lower in comparison to the study done by Tamuno et al. (94\%). ${ }^{23}$ According to WHO it is advised to prescribe drugs belonging to NLEM only but this percentage is lower may be because only selective antihistamines were there in our NLEM . Proper dose, dosage form, frequency, routes of administration, and duration of prescribed antihistamines were properly mentioned in the prescriptions.

\section{CONCLUSION}

Antihistamines, mostly second generation, are commonly prescribed in upper respiratory tract infections in paediatric patients. Indicators like number of drugs per prescription, number of antibiotics per encounter, percentage of injection exposure were on a par with WHO standards. Use of generic name, percentage of drugs from NLEM was much below the recommended standards.

Clinicians should be encouraged to use generic names and include drugs from NLEM. Programme like formation of drug review committees, holding CMEs on rational prescribing, etc., can be organised to strengthen the good aspects and improve the shortcomings in prescribing patterns.

\section{Conflict of interest: None Source(s) of support: None}

\section{REFERENCES}

1. Lunde PKM. The World Health Organisation essential drug concept three years afterwards. In: Turner P, Padgham C, Hedges A, editors. Clinical Pharmacology \& Therapeutics. London: Springer; 1980 (pp. 529-35). [Full Text | DOI]

2. Joseph N, Bharathi DR, Sreenivasa B, Nataraj GR, George N, Safdar M. Prescribing pattern of drugs in upper respiratory tract infections in pediatric outpatients. Int J Contemp Pediatr. 2016 Jul;3(3):1006-08. [Full Text|DOI]

3. Pise HN, Padwal SL, Jadhav RR, Deshmukh VS, Jadhav AD, Kolhe AM. Drug prescribing and dispensing pattern in pediatrics outpatient clinic of a rural tertiary-care teaching hospital. Natl J Physiol Pharm Pharmacol. 2015;5(4):313-7. [Full Text | DOI]

4. Lamichhane DC, Giri BR, Pathak OK, Panta OB, Shankar PR. Morbidity profile and prescribing patterns among outpatients in a teaching hospital in Western Nepal. McGill J Med. 2006 Jul;9(2):126-33. [PubMed | Full Text]

5. Nandimath MK, Ahuja S. Drug prescribing pattern in upper respiratory tract infection in children aged 1-14 years. Int J Pharm Bio Sci. 2012;3(1):299-308. [Full Text]

6. Helms PJ, Ekins Daukes S, Taylor MW, Simpson CR, McLay JS. Utility of routinely acquired primary care data for paediatric disease epidemiology and

pharmacoepidemiology. Br J Clin Pharmacol. 2005 Jun;59(6):684-90. [PubMed | Full Text | DOI]

7. Brown RE, Stevens DR, Haas HL. The physiology of brain histamine. Prog Neurobiol. 2001 Apr;63(6):63772. [PubMed | Full Text | DOI]

8. Ten Eick AP, Blumer JL, Reed MD. Safety of antihistamines in children. Drug Saf. 2001;24(2):11947. [PubMed | Full Text | DOI]

9. Sisay M, Mengistu G, Molla B, Amare F, Gabriel T. Evaluation of rational drug use based on World Health Organization core drug use indicators in selected public hospitals of eastern Ethiopia: A cross sectional study. BMC Health Serv Res. 2017 Feb 23;17(1):161. [PubMed | Full Text | DOI]

10. National list of essential medicines Nepal [Internet]. 2016. [Full Text]

11. Tiwari P, Ahlawat R, Gupta G. Prescription practice in patients of upper respiratory tract infection at a paediatric outpatient clinic in Punjab. Indian J Pharm Pract. 2014 Apr-Jun;7(2):26-32. [Full Text | DOI]

12. Zeru T, Berihu H, Buruh G, Gebrehiwot H. Magnitude and factors associated with upper respiratory tract infection among under-five children in public health institutions of Aksum town, Tigray, northern Ethiopia: An institutional based cross-sectional study. Pan Afr Med J. 2020 Aug 19;36:307. [PubMed | Full Text | DOI] 
13. Tiwari $P$, Ahlawat $R$, Gupta G. Pattern of prescribing at a paediatric outpatient setting in northern India. Indian J Pharm Pract. 2012;5(1):40-4. [Full Text]

14. Kolasani BP, Divyashanthi CM, Sasidharan $P$, Kothandapany SV. Prescription analysis of both $\mathrm{H} 1$ and $\mathrm{H} 2$ antihistamines among in-patients of dermatology department of a tertiary care teaching hospital in a coastal town of south India. Natl J Physiol Pharm Pharmacol 2016;6(6):537-43. [Full Text]

15. González MA, Estes KS. Pharmacokinetic overview of oral second-generation $\mathrm{H} 1$ antihistamines. Int J Clin Pharmacol Ther. 1998 May;36(5):292-300. [PubMed | Full Text]

16. Popov TA, Dumitrascu D, Bachvarova A, Bocsan C, Dimitrov V, Church MK. A comparison of levocetirizine and desloratadine in the histamineinduced wheal and flare response in human skin in vivo. Inflamm Res. 2006 Jun;55(6):241-4. [PubMed | Full Text |DOI]

17. Das B, Sarkar C, Majumder AG. Medication use for paediatric upper respiratory tract infections. Fundam Clin Pharmacol. 2006 Aug;20(4):385-90. [PubMed | Full Text | DOI]
18. Mirza NY, Desai S, Ganguly B. Prescribing pattern in a pediatric out-patient department in Gujarat. Bangladesh J Pharmacol. 2008 Aug;4(1):39-42. [Full Text | DOI]

19. Roy V, Rana P. Prescribing generics: All in a name. Indian J Med Res 2018 May;147:442-4. [PubMed | Full Text |DOI]

20. Senok AC, Ismaeel AY, Al-Qashar FA, Agab WA. Pattern of upper respiratory tract infections and physicians' antibiotic prescribing practices in Bahrain. Med Princ Pract. 2009;18(3):170-4. [Full Text | DOI]

21. Karande $S$, Sankhe $P$, Kulkarni M. Patterns of prescription and drug dispensing. Indian J Pediatr. 2005 Feb;72 (2):117-21. [PubMed | Full Text | DOI]

22. Mittal N, Mittal R, Singh I, Shafiq N, Malhotra S. Drug utilisation study in a tertiary care center: Recommendations for improving hospital drug dispensing policies. Indian J Pharm Sci. 2014 Jul;76(4):308-14. [PubMed | Full Text]

23. Tamuno I, Fadare JO. Drug prescription pattern in a Nigerian tertiary hospital. Trop J Pharmaceut Res. 2012;11(1):146-52. [Full Text | DOI] 